OPEN ACCESS

Edited by:

Rustem Khazipov,

Institut National de la Santé et de la Recherche Médicale (INSERM),

France

Reviewed by:

Randall Keith Powers,

University of Washington,

United States

Nina L. Suresh,

Rehabilitation Institute of

Chicago, United States

${ }^{*}$ Correspondence:

Katharina A. Quinlan

kaquinlan@uri.edu

Received: 17 December 2019 Accepted: 09 March 2020

Published: 25 March 2020

Citation:

Steele PR, Cavarsan CF, Dowaliby L, Westefeld M, Katenka N,

Drobyshevsky A, Gorassini MA and Quinlan KA (2020) Altered Motoneuron Properties Contribute to Motor Deficits in a Rabbit Hypoxia-Ischemia Model of Cerebral Palsy. Front. Cell. Neurosci. 14:69. doi: 10.3389/fncel.2020.00069

\section{Altered Motoneuron Properties Contribute to Motor Deficits in a Rabbit Hypoxia-Ischemia Model of Cerebral Palsy}

\author{
Preston R. Steele ${ }^{1,2}$, Clarissa Fantin Cavarsan ${ }^{2,3}$, Lisa Dowaliby ${ }^{2,3}$, Megan Westefeld ${ }^{3}$, \\ N. Katenka ${ }^{4}$, Alexander Drobyshevsky ${ }^{5}$, Monica A. Gorassini ${ }^{6}$ and \\ Katharina A. Quinlan $2,3,7$ *
}

${ }^{1}$ Interdepartmental Neuroscience Program, University of Rhode Island, Kingston, RI, United States, ${ }^{2}$ George and Anne Ryan Institute for Neuroscience, University of Rhode Island, Kingston, RI, United States, ${ }^{3}$ Department of Biomedical and Pharmaceutical Sciences, College of Pharmacy, University of Rhode Island, Kingston, Rl, United States, ${ }^{4}$ Department of Computer Science and Statistics, University of Rhode Island, Kingston, Rl, United States, ${ }^{5}$ Northshore University Health System Research Institute, Evanston, IL, United States, ${ }^{6}$ Department of Biomedical Engineering, University of Alberta, Edmonton, AB, Canada, 'Department of Physiology, Northwestern University Feinberg School of Medicine, Chicago, IL, United States

Cerebral palsy (CP) is caused by a variety of factors attributed to early brain damage, resulting in permanently impaired motor control, marked by weakness and muscle stiffness. To find out if altered physiology of spinal motoneurons (MNs) could contribute to movement deficits, we performed whole-cell patch-clamp in neonatal rabbit spinal cord slices after developmental injury at $79 \%$ gestation. After preterm hypoxia-ischemia $(\mathrm{HI})$, rabbits are born with motor deficits consistent with a spastic phenotype including hypertonia and hyperreflexia. There is a range in severity, thus kits are classified as severely affected, mildly affected, or unaffected based on modified Ashworth scores and other behavioral tests. At postnatal day (P)0-5, we recorded electrophysiological parameters of $40 \mathrm{MNs}$ in transverse spinal cord slices using whole-cell patch-clamp. We found significant differences between groups (severe, mild, unaffected and sham control MNs). Severe HI MNs showed more sustained firing patterns, depolarized resting membrane potential, and fired action potentials at a higher frequency. These properties could contribute to muscle stiffness, a hallmark of spastic CP. Interestingly altered persistent inward currents (PICs) and morphology in severe HI MNs would dampen excitability (depolarized PIC onset and increased dendritic length). In summary, changes we observed in spinal MN physiology likely contribute to the severity of the phenotype, and therapeutic strategies for CP could target the excitability of spinal MNs.

Keywords: cerebral palsy, hypoxia-ischemia, frequency-current, persistent inward current, rabbit

\section{INTRODUCTION}

Cerebral palsy (CP) is not well understood, despite its prevalence and seriousness. There exist only a few evidence-based treatments for CP: the effectiveness of many currently used therapeutic strategies is unclear (Novak et al., 2013; Wimalasundera and Stevenson, 2016). Recent clinical advances include use of magnesium sulfate and hypothermia after hypoxic-ischemic 
encephalopathy to acutely reduce neural damage (Yager et al., 1993; Thoresen et al., 1996; Magee et al., 2011; Rouse and Gibbins, 2013), but little basic research is devoted to addressing symptoms after they arise. Part of the problem in treating CP may be the diversity of causes including neonatal stroke, placental insufficiency, preterm birth, inflammation, traumatic injury, difficulties during birth and many other contributing factors (MacLennan and International Cerebral Palsy Task Force, 1999; Graham et al., 2016). Another problem could be that modeling the condition in animals is complicated, and while rodent models are useful for the development of neuroprotective strategies, larger animal models are needed to study motor deficits (Clowry et al., 2014; Cavarsan et al., 2019).

Loss of corticospinal control of movement is considered causative of motor deficits in $\mathrm{CP}$, but little investigation into the precise effect on spinal circuits has been conducted. A notable exception is the work of John H. Martin and colleagues, who have documented changes in corticospinal synaptic connectivity in specific spinal laminae and loss of cholinergic interneurons after either cortical silencing or lesioning the corticospinal tract (Martin et al., 1999; Li and Martin, 2000; Friel and Martin, 2005, 2007; Friel et al., 2012; Jiang et al., 2016, 2018). Another important study showed changes in parvalbumin-positive spinal interneurons after cortical silencing in development (Clowry et al., 2004; Clowry, 2007). Both of these interneuron classes (parvalbumin-positive and cholinergic) are synaptically connected to spinal MNs and could contribute to altered motor output after developmental injury. Based on these foundational studies, we hypothesized that altering development with hypoxia-ischemia (HI) injury would also alter the development of MNs, specifically the electrophysiological properties governing excitability in spinal MNs. We further hypothesized that changes in excitability would correspond/contribute to the severity of motor deficits. In short, that altered activity of spinal MNs could contribute to muscle stiffness and spasticity.

To assess changes in the intrinsic properties of spinal MNs, we used the rabbit HI model of CP (Derrick et al., 2004). It's been shown in previous studies that $\mathrm{HI}$ injury during late gestation in rabbits can result in a variety of neurologic and muscular damage, including muscle stiffness (Derrick et al., 2004), loss of neurons in cortical layers 3 and 5, white matter injury, thinning of the corticospinal tract (Buser et al., 2010), cell death in the spinal cord and decreased numbers of spinal MNs (Drobyshevsky and Quinlan, 2017), increased sarcomere length, decreased muscle mass and hyperreflexia (Synowiec et al., 2019). There is also an increase in spinal monoamines which could increase the excitability of spinal neurons and thus promote spasticity (Bellot et al., 2014; Drobyshevsky et al., 2015). Thus, changes observed in spinal $\mathrm{MNs}$ in the rabbit model could be directly compared to motor deficits.

Changes in $\mathrm{MN}$ physiology are likely to contribute to motor impairment in CP, yet this has not been directly assessed in any animal models. Thus, we assessed electrophysiological parameters in spinal MNs in neonatal rabbits after sham surgery or hypoxic-ischemic insult during development.

\section{MATERIALS AND METHODS}

All rabbits were used according to National Institutes of Health guide for the care and use of laboratory animals, and the University of Rhode Island's, Northwestern University's and Northshore University Health System's Animal Care and Use Committee guidelines. Pregnant New Zealand White rabbits (Charles River Laboratories, Inc. Wilmington, MA, USA), underwent HI procedures as described previously (Derrick et al., 2004; Buser et al., 2010). Briefly, the procedure was performed at $\sim 80 \%$ gestation (day 25 of gestation, or E25), a time when $\mathrm{HI}$ has been found to result in the greatest degree of white matter injury and corticospinal tract thinning. Dams were anesthetized, and the left femoral artery was isolated. A Fogarty balloon catheter was inserted into the femoral and advanced to the level of the descending aorta, above the uterine arteries and inflated for $40 \mathrm{~min}$. Sham animals underwent the same procedures but without the inflation of the catheter. After the procedure, the dam recovered and later gave birth to kits with $\mathrm{HI}$ injuries. Categorization of the severity of the phenotype was performed by a blinded observer, using a modified Ashworth scale, observation/tests for activity, locomotion, posture, righting reflex, muscle tone (as described in Derrick et al., 2004). Kits could be given a maximum score of 6 (normal posture, righting and joint resistance). Since, there was a large variation in the severity of motor deficits, HI kits were divided into three groups: HI unaffected (scores were the same range as control kits, 5-6), HI mild (scores 3-4), HI severe (scores 1-2). One rabbit kit which was affected by HI but displayed a phenotype of hypotonia instead of hypertonia was removed from the data set. All other kits included in this study displayed a hypertonic phenotype if affected by HI.

\section{Patch Clamp}

Whole-cell patch-clamp was performed similarly to previously published work (Quinlan et al., 2011) from P0-5. Briefly, horizontal spinal cord slices $350 \mu \mathrm{m}$ thick were obtained using a Leica 1,000 vibratome. Slices were incubated for $1 \mathrm{~h}$ at $30^{\circ} \mathrm{C}$ and recordings were performed at room temperature. During recording, slices were perfused with oxygenated $\left(95 \% \mathrm{O}_{2}\right.$ and $5 \% \mathrm{CO}_{2}$ ) modified Ringer's solution containing (in $\mathrm{mM}$ ): $111 \mathrm{NaCl}, 3.09 \mathrm{KCl}, 25.0 \mathrm{NaHCO}_{3}, 1.10 \mathrm{KH}_{2} \mathrm{PO}_{4}, 1.26 \mathrm{MgSO}_{4}$, $2.52 \mathrm{CaCl}_{2}$, and 11.1 glucose at $2 \mathrm{ml} / \mathrm{min}$. Whole-cell patch electrodes (1-3 $\mathrm{M} \Omega$ ) contained (in $\mathrm{mM}$ ) 138 K-gluconate, 10 HEPES, 5 ATP-Mg, 0.3 GTP-Li and Texas Red dextran (150 $\mu \mathrm{M}, 3,000 \mathrm{MW})$. PICs were measured in voltage-clamp mode with holding-potential of $-90 \mathrm{mV}$ and depolarizing voltage ramps of both $36 \mathrm{mV} / \mathrm{s}$ and $11.25 \mathrm{mV} / \mathrm{s}$ bringing the cell to $0 \mathrm{mV}$ in $2.5 \mathrm{~s}$ or $8 \mathrm{~s}$, respectively and then back to the holding potential in the following $2.5 \mathrm{~s}$ or $8 \mathrm{~s}$. Input resistance was measured from the slope of the leak current near the holding potential. Capacitance was measured with Multiclamp's whole-cell capacitance compensation function. Resting membrane potential was measured in voltage-clamp as the voltage at which there is $0 \mathrm{pA}$ of injected current in the descending ramp. In current clamp, frequency-current measurements were obtained from current ramps. The first 

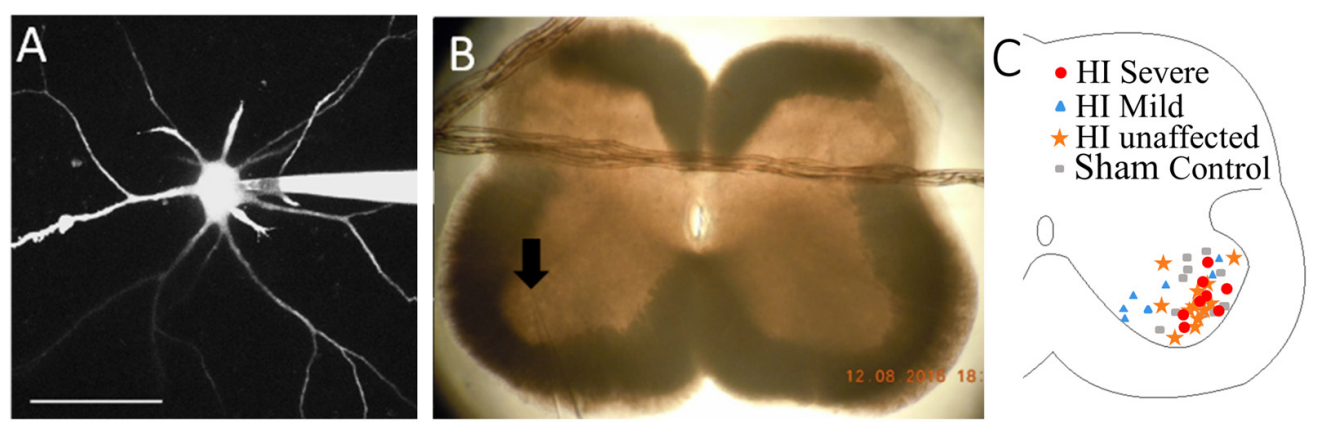

FIGURE 1 | Patch clamp of spinal motoneurons (MNs) with dye-filling via patch electrode as shown in panel (A). Scale bar = $100 \mu \mathrm{m}$. (B) Placement of patch electrode (at arrow) within the slice is captured with a photo. (C) Map of recorded MNs within medial and lateral motor pools. Red circles = HI Severe, blue triangles $=\mathrm{HI}$ Mild, yellow stars $=\mathrm{HI}$ unaffected, gray rectangles $=$ Sham Controls.

spike on the current ramp was used to measure the properties of action potentials. The threshold voltage was defined as the voltage at which the action potential slope exceeds $10 \mathrm{~V} / \mathrm{s}$. Rate of rise and fall of the action potential were measured as peak and trough of the first derivative of the action potential. The duration of the action potential was measured at half-peak (defined as the midpoint between overshoot and threshold voltages). Depolarizing current steps of varying amplitude were used to find maximum firing rates (near depolarization block) and to measure after-spike afterhyperpolarization (in single spikes elicited near-threshold). Hyperpolarizing current steps (typically between -850 and $-1,250 \mathrm{pA}$ ) were used to measure hyperpolarization-activated sag currents $\left(\mathrm{I}_{\mathrm{H}}\right)$. Neuron selection: neurons were targeted in $\mathrm{MN}$ pools mainly from cervical and lumbar regions of the cord and were removed from the data set if their resting membrane potential was more depolarized than $-45 \mathrm{mV}$ in current clamp.

\section{Imaging}

After electrophysiological measurements were obtained, MNs were imaged to assess anatomical development, and photos were obtained of the electrode placement within the spinal cord slice, as shown in Figure 1. Images were acquired with a Nikon microscope fitted with a $40 \times$ water-dipping objective lens and two-photon excitation fluorescence microscopy performed with a galvanometer-based Coherent Chameleon Ultra II laser. To optimize the excitation of red/green fluorophores, the laser was tuned to $900 \mathrm{~nm}$. 3D reconstructions of $\mathrm{MNs}$ were created using Neurolucida $360^{\circ}$ software. It is likely that some processes extended past the surface of the slice and were excluded from reconstructions. However, since this was the case for all MNs in this study it is unlikely to have an impact on the findings.

\section{Statistics}

All variables were checked for normality and homogeneity (using Shapiro-Wilk and Levene's tests). The variables that were parametric (normal and homogenous) were run with one-way Analysis of Variance (ANOVA) and then assessed post hoc with a Tukey test for between-group significance. The non-parametric variables were run with the Kruskal-Wallis test followed by Dunn's test as a post hoc analysis to assess significance between groups, adjusting the $p$-value for multiple comparisons. The analysis was done using $\mathrm{R}$ software for determining the significance of parameters over groups, according to their injury classification (sham, HI unaffected, HI mildly affected, and HI severely affected). Injury classification, age of the kit (P0-P5), and spinal cord region (cervical, thoracic, lumbar or sacral) were all tested. Significance was determined by $p$-values $\leq 0.05$.

\section{RESULTS}

After HI surgery was performed in pregnant dams at $79 \%$ gestation, kits were born naturally about a week later. At ages $\mathrm{P} 0$, neonates were rated as unaffected, mildly affected or severely affected. Since, there was a large variation in the severity of motor deficits, HI kits were divided into three groups: HI unaffected, HI mild, HI severe. Experiments were all performed in the first 5 days of life. Over 40 spinal MNs were patched in transverse spinal cord slices, and over 40 parameters were measured from each. To determine the significance of the variables, a one-way ANOVA was performed to find differences among three factors: (1) injury classification (sham control, HI unaffected, HI mildly affected, and HI severely affected); (2) age (postnatal day 0-5); and (3) spinal region (cervical through sacral). All data, including mean, standard deviation, group size, and the $p$-value is included in table format (Tables 1-5 and Supplementary Tables S1, S2).

\section{HI MNs Show Sustained Firing and Higher Firing Frequency}

In rabbit kits severely injured by $\mathrm{HI}$, MNs had significantly increased sustained firing. The frequency current (F-I) relationship was measured using the current ramps, as shown in Figure 2. Depolarizing current ramps are used to evoke firing, and current at onset and offset of firing $\left(\mathrm{I}_{\mathrm{ON}}\right.$ and $\left.\mathrm{I}_{\mathrm{OFF}}\right)$ determine $\Delta \mathrm{I}$. In sham control MNs, $\Delta \mathrm{I}$ was larger and always a positive value, indicating firing ceased at a higher current amplitude on the descending ramp than the current level that elicited firing on the ascending ramp (see Figure 2A). Severe HI MNs had a smaller, and usually negative $\Delta \mathrm{I}$, revealing increasingly sustained firing (see Figure 2B). Also, resting membrane potential was significantly more depolarized in $\mathrm{HI} \mathrm{MNs}$ than sham controls 
TABLE 1 | Frequency-current characteristics.

\begin{tabular}{|c|c|c|c|c|c|}
\hline Variable & Condition & Mean & $S D$ & $N$ & $p$ \\
\hline \multirow[t]{4}{*}{ ION $(p A)$} & Sham & 213 & 149 & 9 & \\
\hline & HI Unaffected & 627 & 475 & 12 & 0.129 \\
\hline & HI Mild & 422 & 458 & 10 & 0.507 \\
\hline & HI Severe & 459 & 375 & 8 & 0.450 \\
\hline \multirow[t]{4}{*}{ IOFF $(p A)$} & Sham & 416 & 357 & 9 & \\
\hline & HI Unaffected & 768 & 538 & 12 & 0.545 \\
\hline & HI Mild & 509 & 319 & 10 & 1.000 \\
\hline & HI Severe & 443 & 452 & 8 & 1.000 \\
\hline \multirow[t]{4}{*}{$\Delta I(p A)$} & Sham & 219 & 224 & 9 & \\
\hline & HI Unaffected & 141 & 159 & 12 & 0.496 \\
\hline & HI Mild & 88 & 279 & 10 & 0.106 \\
\hline & HI Severe & -16 & 84 & 8 & $0.046^{*}$ \\
\hline \multirow[t]{4}{*}{ FI Slope $(\mathrm{Hz} / \mathrm{nA})$} & Sham & 23 & 18 & 9 & \\
\hline & HI Unaffected & 13 & 4 & 12 & 0.557 \\
\hline & HI Mild & 23 & 23 & 10 & 0.945 \\
\hline & HI Severe & 20 & 9 & 8 & 0.370 \\
\hline \multirow[t]{4}{*}{ Threshold (mV) } & Sham & -35.8 & 7.2 & 9 & \\
\hline & HI Unaffected & -32.2 & 8.0 & 12 & 0.279 \\
\hline & HI Mild & -36.3 & 7.1 & 10 & 0.879 \\
\hline & HI Severe & -29.9 & 6.7 & 8 & 0.107 \\
\hline \multirow{4}{*}{$\begin{array}{l}\text { Maximum } \\
\text { instantaneous firing } \\
\text { frequency }(\mathrm{Hz})\end{array}$} & Sham & 98 & 28 & 9 & \\
\hline & HI Unaffected & 106 & 32 & 12 & 0.556 \\
\hline & HI Mild & 129 & 33 & 10 & $0.025^{*}$ \\
\hline & HI Severe & 129 & 23 & 8 & $0.045^{*}$ \\
\hline \multirow{4}{*}{$\begin{array}{l}\text { Maximum steady state } \\
\text { firing frequency }(\mathrm{Hz})\end{array}$} & Sham & 30 & 10 & 9 & \\
\hline & HI Unaffected & 36 & 13 & 12 & 0.552 \\
\hline & HI Mild & 45 & 18 & 10 & 0.346 \\
\hline & HI Severe & 37 & 13 & 8 & 0.559 \\
\hline \multirow{4}{*}{$\begin{array}{l}\text { Resting membrane } \\
\text { potential }(\mathrm{mV})\end{array}$} & Sham & -60.8 & 6.4 & 9 & \\
\hline & HI Unaffected & -53.9 & 11.3 & 13 & 0.070 \\
\hline & HI Mild & -58.5 & 4.3 & 10 & 0.556 \\
\hline & HI Severe & -50.5 & 9.1 & 8 & $0.017^{*}$ \\
\hline
\end{tabular}

*Significant difference to sham animals.

(see Figure 2F). Another significant difference in severe HI MNs is the instantaneous firing rate, as shown in Figure 3. At the start of a depolarizing current step, the peak (instantaneous) firing rate is higher in severe HI MNs than sham controls (see Figure 3B). Sustained firing is also apparent in Figure 3C, in the second current step which evokes a brief burst of action potentials followed by depolarization block in both MNs. The severe $\mathrm{HI} \mathrm{MN}$ recovers and resumes firing while the sham control MN remains in depolarization block. Mean values for both instantaneous and steady-state parameters are shown in bar graphs (Figures 3D,E). Significant changes in MN physiology were present in severely affected animals: post hoc analysis showed significant changes between sham and severe HI MNs in $\triangle \mathrm{I}, \mathrm{RMP}$, and instantaneous firing rate. The instantaneous firing rate also reached significance in mild HI MNs vs. sham. No significant changes were present in $\mathrm{HI}$ unaffected MNs in any properties. While these parameters $(\Delta \mathrm{I}, \mathrm{RMP}$, and instantaneous firing rate) suggest increased excitability in HI-injured MNs, there was no significant change in the threshold, $\mathrm{I}_{\mathrm{ON}}$, or $\mathrm{I}_{\mathrm{OFF}}$ in HI MNs. Thus, MNs from severely affected kits should not be classified as hyperexcitable per se, since they begin
TABLE 2 | Persistent inward current characteristics (5 s ramp).

\begin{tabular}{|c|c|c|c|c|c|}
\hline Variable & Condition & Mean & $S D$ & $N$ & $p$ \\
\hline \multirow{4}{*}{$\begin{array}{l}\text { Norm PIC amp } \\
(\mathrm{pA} / \mathrm{pF})\end{array}$} & Sham & -2.10 & 2.44 & 9 & \\
\hline & HI Unaffected & -1.45 & 0.81 & 13 & 0.852 \\
\hline & HI Mild & -1.86 & 1.02 & 9 & 0.988 \\
\hline & HI Severe & -1.22 & 0.41 & 8 & 0.923 \\
\hline \multirow[t]{4}{*}{ PIC onset (mV) } & Sham & -42.9 & 7.3 & 9 & \\
\hline & HI Unaffected & -37.4 & 6.7 & 13 & 0.200 \\
\hline & HI Mild & -38.7 & 8.1 & 9 & 0.337 \\
\hline & HI Severe & -38.1 & 10.6 & 8 & 0.278 \\
\hline \multirow[t]{4}{*}{$\mathrm{PIC} \max (\mathrm{mV})$} & Sham & -30.0 & 7.3 & 9 & \\
\hline & HI Unaffected & -22.9 & 7.6 & 13 & 0.081 \\
\hline & HI Mild & -22.6 & 7.4 & 9 & 0.066 \\
\hline & HI Severe & -23.1 & 9.2 & 8 & 0.093 \\
\hline \multirow{4}{*}{$\begin{array}{l}\text { PIC negative slope } \\
\text { range }(\mathrm{mV})\end{array}$} & Sham & 12.9 & 3.1 & 9 & \\
\hline & HI Unaffected & 14.4 & 2.7 & 13 & 0.458 \\
\hline & HI Mild & 16.0 & 2.8 & 9 & 0.250 \\
\hline & HI Severe & 15.0 & 3.1 & 8 & 0.462 \\
\hline \multirow[t]{4}{*}{ PIC amplitude (pA) } & Sham & -280 & 185 & 9 & \\
\hline & HI Unaffected & -366 & 195 & 13 & 0.344 \\
\hline & HI Mild & -417 & 273 & 9 & 0.162 \\
\hline & HI Severe & -344 & 115 & 8 & 0.525 \\
\hline \multirow[t]{4}{*}{ Capacitance (pF) } & Sham & 192 & 98 & 9 & \\
\hline & HI Unaffected & 259 & 45 & 13 & 0.167 \\
\hline & HI Mild & 214 & 77 & 10 & 0.471 \\
\hline & HI Severe & 282 & 0 & 8 & $0.028^{*}$ \\
\hline \multirow{4}{*}{$\begin{array}{l}\text { Input resistance } \\
(\mathrm{M} \Omega)\end{array}$} & Sham & 60 & 35 & 9 & \\
\hline & HI Unaffected & 40 & 16 & 13 & 1.00 \\
\hline & HI Mild & 56 & 34 & 10 & 1.00 \\
\hline & HI Severe & 54 & 30 & 8 & 0.965 \\
\hline
\end{tabular}

*Significant difference to sham animals.

firing with the same depolarizing input and at the same voltage threshold.

\section{Changes in Spike Properties and Subthreshold Responses Were Not Present}

A complete analysis of $\mathrm{I}_{\mathrm{H}}$ (sag and rebound currents), action potential parameters, and after-spike after-hyperpolarization (AHP) was performed and no significant differences in these parameters were found between groups. All data is included in Supplementary Tables S1, S2.

\section{Persistent Inward Currents Suggest Excitability Is Dampened After HI}

PICs were significantly affected by hypoxia-ischemia (HI), revealing that intrinsic excitability may be dampened. PICs were measured using both short (5 s) and long (16 s) protocols, which can preferentially activate and inactivate $\mathrm{Na}^{+}$and $\mathrm{Ca}^{2+}$ mediated PICs. The different protocols yielded different results. For example, as shown in Figure 4, voltage dependence (PIC onset and PIC Max) was unchanged in the PICs evoked using a short 5-s voltage ramp HI severe MNs. Using longer voltage ramps (16 s), PIC onset was significantly depolarized in HI severe MNs compared to sham (see Tables 2, 3). Since the change in PIC onset was more pronounced in longer ramps this could suggest an altered balance of $\mathrm{Na}^{+}$and $\mathrm{Ca}^{2+}$ channel activation or altered activation/inactivation of these channels 
TABLE 3 | Persistent inward current characteristics (16 s ramp).

\begin{tabular}{|c|c|c|c|c|c|}
\hline Variable & Condition & Mean & $S D$ & $N$ & $p$ \\
\hline \multirow{4}{*}{$\begin{array}{l}\text { Norm PIC amp } \\
(\mathrm{pA} / \mathrm{pF})\end{array}$} & Sham & -2.32 & 2.77 & 6 & \\
\hline & HI Unaffected & -1.58 & 0.90 & 13 & 0.953 \\
\hline & HI Mild & -1.73 & 0.94 & 9 & 0.706 \\
\hline & HI Severe & -1.03 & 0.50 & 8 & 0.735 \\
\hline \multirow[t]{4}{*}{ PIC onset $(\mathrm{mV})$} & Sham & -47.2 & 6.0 & 6 & \\
\hline & HI Unaffected & -39.7 & 6.3 & 13 & 0.086 \\
\hline & HI Mild & -40.9 & 9.7 & 9 & 0.169 \\
\hline & HI Severe & -35.0 & 11.5 & 8 & $0.013^{*}$ \\
\hline \multirow[t]{4}{*}{$\mathrm{PIC} \max (\mathrm{mV})$} & Sham & -27.8 & 9.4 & 6 & \\
\hline & HI Unaffected & -21.4 & 7.4 & 13 & 0.175 \\
\hline & HI Mild & -24.2 & 9.9 & 9 & 0.479 \\
\hline & HI Severe & -18.3 & 11.1 & 8 & 0.071 \\
\hline \multirow{4}{*}{$\begin{array}{l}\text { PIC negative slope } \\
\text { range }(\mathrm{mV})\end{array}$} & Sham & 19.5 & 6.0 & 6 & \\
\hline & HI Unaffected & 18.3 & 3.2 & 13 & 0.927 \\
\hline & HI Mild & 16.6 & 2.4 & 9 & 1.000 \\
\hline & HI Severe & 16.7 & 4.1 & 8 & 0.872 \\
\hline \multirow[t]{4}{*}{ PIC amplitude (pA) } & Sham & -315 & 189 & 6 & \\
\hline & HI Unaffected & -389 & 227 & 13 & 0.215 \\
\hline & HI Mild & -397 & 254 & 9 & 0.310 \\
\hline & HI Severe & -323 & 113 & 8 & 0.802 \\
\hline \multicolumn{6}{|c|}{ *Significant difference to sham animals. } \\
\hline Variable & Condition & Mean & $S D$ & $N$ & $p$ \\
\hline \multirow{4}{*}{$\begin{array}{l}\text { Largest cross-sectional } \\
\text { area }\left(\mu \mathrm{m}^{2}\right)\end{array}$} & Sham & 577 & 316 & 9 & \\
\hline & HI Unaffected & 756 & 287 & 12 & 1.000 \\
\hline & HI Mild & 676 & 307 & 10 & 0.277 \\
\hline & HI Severe & 694 & 338 & 8 & 1.000 \\
\hline \multirow[t]{4}{*}{ Surface area $\left(\mu \mathrm{m}^{2}\right)$} & Sham & 2,599 & 1,153 & 9 & \\
\hline & HI Unaffected & 3,609 & 2,083 & 12 & 0.591 \\
\hline & HI Mild & 2,489 & 1,129 & 10 & 0.447 \\
\hline & HI Severe & 2,582 & 851 & 8 & 0.155 \\
\hline \multirow[t]{4}{*}{ Volume $\left(\mu \mathrm{m}^{3}\right)$} & Sham & 12,306 & 8,219 & 9 & \\
\hline & HI Unaffected & 23,735 & 28,313 & 12 & 0.716 \\
\hline & HI Mild & 12,445 & 7,963 & 10 & 0.255 \\
\hline & HI Severe & 12,264 & 6,308 & 8 & 0.826 \\
\hline
\end{tabular}

(see "Discussion" section). Change in the magnitude of the PIC was not observed outright in either of the protocols: the magnitude of the currents was similar between groups (see Figure 4 and Tables 2, 3). Intrinsic properties including capacitance (which significantly increased in HI MNs compared to sham) and input resistance of all $\mathrm{MNs}$ are included in Table 2.

\section{Morphology Affected by HI Injury}

Morphology of MNs was assessed in all patched neurons, as shown in Figure 5. As suggested by the significantly larger whole-cell capacitance, there were changes in $\mathrm{MN}$ morphology after HI injury. The soma size was unchanged: there were no significant differences between groups in soma's largest crosssectional area (Figure 5D) or other measurements of soma size (Table 4). There was, however, a significant increase in dendrite length in $\mathrm{HI}$ injured MNs compared to sham controls (Figure 5E), which could account for changes in electrical
TABLE 5 | Dendrite characteristics.

\begin{tabular}{|c|c|c|c|c|c|}
\hline Variable & Condition & Mean & $S D$ & $N$ & $p$ \\
\hline \multirow[t]{4}{*}{ Number of dendrites } & Sham & 7.7 & 2.8 & 9 & \\
\hline & HI Unaffected & 9.5 & 1.4 & 12 & 0.089 \\
\hline & HI Mild & 10.1 & 2.9 & 10 & 0.360 \\
\hline & HI Severe & 10.1 & 2.5 & 8 & 0.128 \\
\hline \multirow[t]{4}{*}{ Nodes } & Sham & 14.8 & 14.1 & 9 & \\
\hline & HI Unaffected & 14.7 & 11.5 & 12 & 0.909 \\
\hline & HI Mild & 13.5 & 5.7 & 10 & 0.800 \\
\hline & HI Severe & 17.0 & 8.9 & 8 & 1.000 \\
\hline \multirow[t]{4}{*}{ Length ( $\mu \mathrm{m})$} & Sham & 1,103 & 649 & 9 & \\
\hline & HI Unaffected & 1,422 & 664 & 12 & 0.346 \\
\hline & HI Mild & 1,443 & 537 & 10 & 0.591 \\
\hline & HI Severe & 1,744 & 521 & 8 & $0.050^{*}$ \\
\hline \multirow[t]{4}{*}{ Mean length $(\mu \mathrm{m})$} & Sham & 140 & 67 & 9 & \\
\hline & HI Unaffected & 149 & 67 & 12 & 0.947 \\
\hline & HI Mild & 144 & 32 & 10 & 0.992 \\
\hline & HI Severe & 178 & 57 & 8 & 0.169 \\
\hline \multirow[t]{4}{*}{ Surface area $\left(\mu \mathrm{m}^{2}\right)$} & Sham & 6,264 & 3,842 & 9 & \\
\hline & HI Unaffected & 9,667 & 7,000 & 12 & 0.649 \\
\hline & HI Mild & 7,537 & 3,293 & 10 & 0.526 \\
\hline & HI Severe & 9,868 & 5,384 & 8 & 0.698 \\
\hline \multirow[t]{4}{*}{ Mean surface area $\left(\mu \mathrm{m}^{2}\right)$} & Sham & 792 & 414 & 9 & \\
\hline & HI Unaffected & 1,024 & 772 & 12 & 0.919 \\
\hline & HI Mild & 740 & 159 & 10 & 0.537 \\
\hline & HI Severe & 1,012 & 603 & 8 & 0.612 \\
\hline \multirow[t]{4}{*}{ Volume $\left(\mu \mathrm{m}^{3}\right)$} & Sham & 3,614 & 2,642 & 9 & \\
\hline & HI Unaffected & 6,926 & 7,512 & 12 & 0.807 \\
\hline & HI Mild & 4,073 & 2,406 & 10 & 1.000 \\
\hline & HI Severe & 5,844 & 5,239 & 8 & 0.664 \\
\hline \multirow[t]{4}{*}{ Mean volume $\left(\mu \mathrm{m}^{3}\right)$} & Sham & 451 & 295 & 9 & \\
\hline & HI Unaffected & 743 & 836 & 12 & 0.771 \\
\hline & HI Mild & 390 & 129 & 10 & 0.847 \\
\hline & HI Severe & 605 & 587 & 8 & 0.917 \\
\hline
\end{tabular}

*Significant difference to sham animals.

properties. Since, we recorded from motor pools throughout the spinal cord (cervical through sacral), there was a large amount of variability within our data set. Future studies in our lab focus on the analysis of specific motor pools. All data on dendritic morphology is included in Table 5.

\section{Age and Spinal Region}

No significant changes in $\mathrm{MN}$ properties were found due to the spinal region. Postnatal age had a significant effect on the following properties: input resistance (decrease with age), action potential size $(\mathrm{mV})$, rate of rise and rate of fall (all increase with age), 5 s PIC amplitude (increase with age), and normalized PIC (PIC/Cap; current density increased with age for both 5 and $16 \mathrm{~s}$ ramps). These results are in line with previous studies on embryonic and postnatal maturation of MNs.

\section{DISCUSSION}

\section{Summary}

Electrophysiological properties of spinal $\mathrm{MNs}$ are altered by developmental HI injury, and the magnitude of changes is correlated to the severity of motor deficits. Specifically, these changes include increased sustained firing and a higher firing rate. These changes could indicate increased excitability and would contribute to muscle stiffness that is common in spastic 

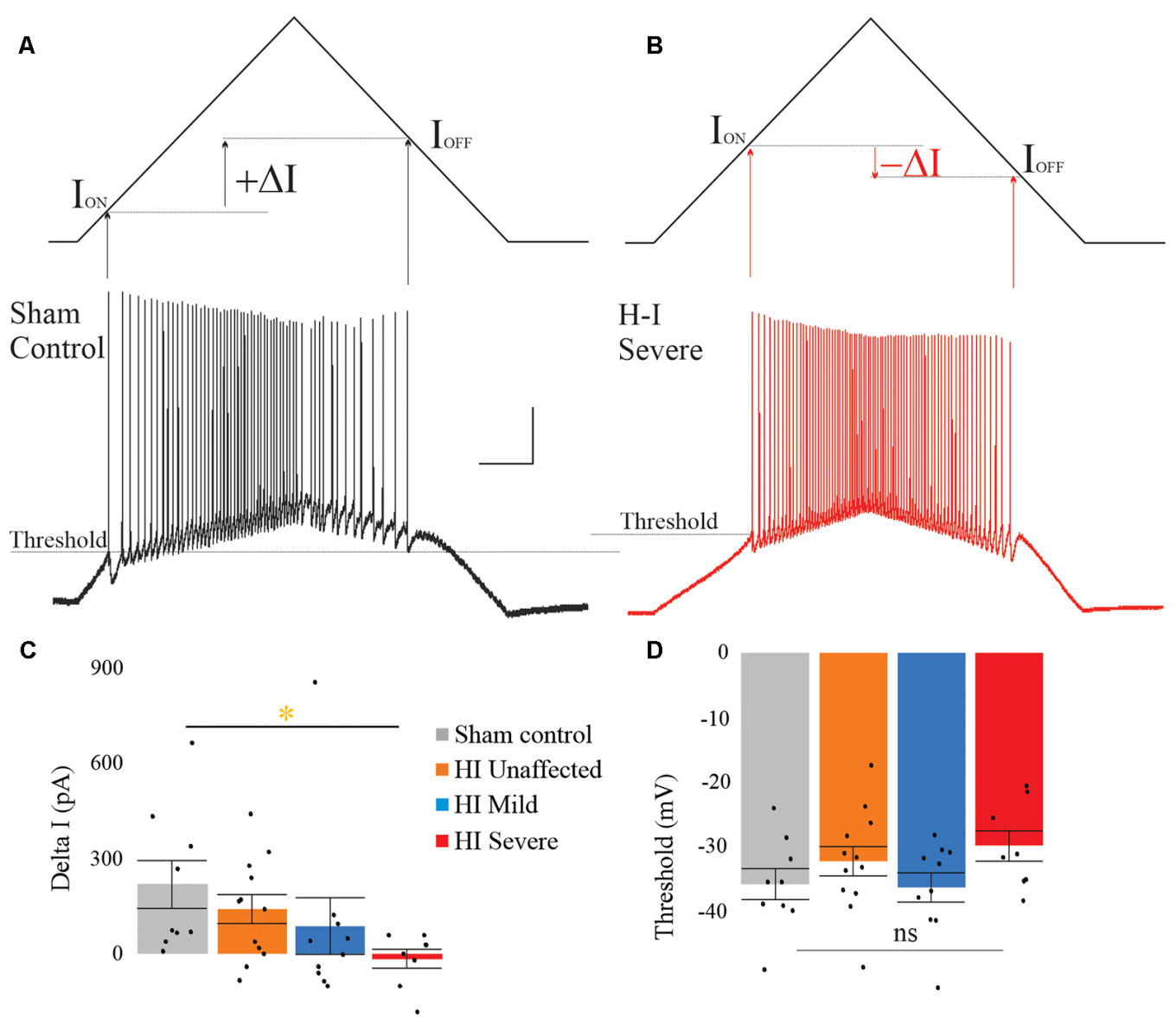

E

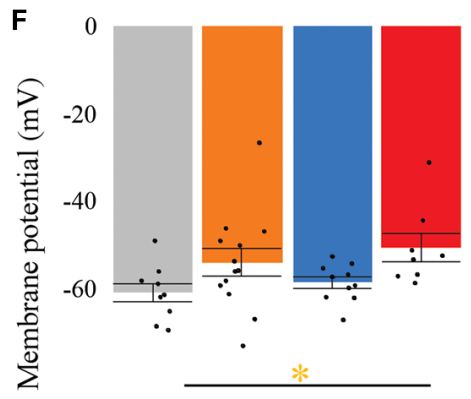

FIGURE 2 | Severe HI MNs show more sustained firing than sham control MNs, and a more depolarized resting membrane potential. Control MNs (A) have larger values for $\Delta \mathrm{l}$ compared to severe $\mathrm{HI}$ (B). Average $\Delta \mathrm{l}$ and threshold are shown in panels (C) and (D) for all groups. The frequency current relationship (E) was not significantly different between groups. Resting membrane potential was significantly more depolarized in $\mathrm{HI}$ severe MNs than sham control MNs (F). Error bars = SEM. Scale bars in $(\mathbf{A})=20 \mathrm{mV}$ (vertical) and $0.5 \mathrm{~s}$ (horizontal) and applies to panels $(\mathbf{A}, \mathbf{B})$.

CP. However, concomitant changes in PIC onset and longer dendritic length could serve to dampen excitability and could contribute to weakness. Since traditional views of CP largely view motor dysfunction as a result of the damaged motor cortex improperly signaling to spinal neurons, our new evidence suggests this is only part of the problem. Spinal MNs are not developing the same after $\mathrm{HI}$ and show an overall change in intrinsic properties. Whether these changes are directly due to the HI insult or indirectly due to downstream effects must be determined by future work.

\section{Contribution of Spinal Motoneurons to Dysfunction in Cerebral Palsy}

Here, we show that MNs show altered excitability after HI injury, including elevated resting potential, and more sustained firing. Previous work showed that after HI injury in rabbits there were also fewer spinal $\mathrm{MNs}$, and spinal interneurons in lamina VII were undergoing apoptosis (Drobyshevsky and Quinlan, 2017). After the loss of corticospinal projections, it was recently found that the spinal cholinergic interneurons which give rise to C boutons on MNs are lost (Jiang et al., 2016, 

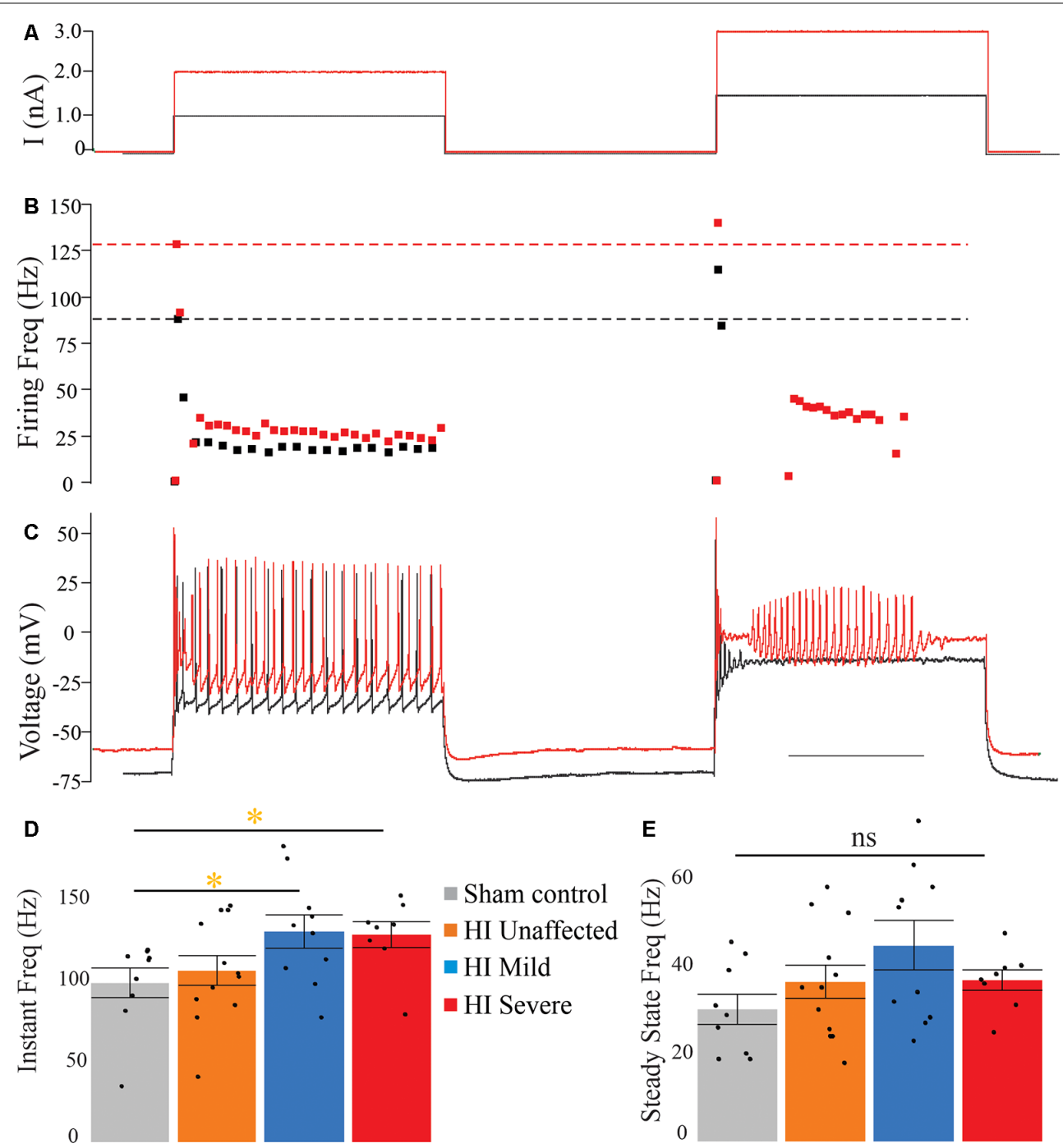

FIGURE 3 | Instantaneous firing frequency is increased in severe HI MNs. Depolarizing current steps (A) evoked action potentials (C) in a typical sham control (black trace) and severe $\mathrm{HI}$ (red trace) MNs. (B) Dotted lines show peak firing frequency of MNs in panel (C). (D) Average instantaneous and (E) steady-state firing frequency are shown for all groups. Error bars = SEM. Scale bar in $(\mathbf{C})=0.5 \mathrm{~s}$ and applies to panels $(\mathbf{A}-\mathbf{C})$.

2018, 2019). Taken together this data suggests spinal circuits are: (1) just as vulnerable to HI injury as the developing cortex; and (2) potentially functioning with fewer neurons and altered circuitry. In addition to fewer neurons, there is also atrophy of the muscles which could contribute to motor deficits in CP. In mice, rabbits, and humans, muscle atrophy appears along with losses in numbers of MNs (Han et al., 2013; Marciniak et al., 2015; Drobyshevsky and Quinlan, 2017; Brandenburg et al., 2018). Recent work has shown similar changes to muscle architecture in the rabbit HI model of CP to humans, including atrophy, muscle shortening, and longer sarcomere length. Increased muscle stiffness in rabbits affected by HI was found even after administration of anesthetic-indicating some muscle stiffness is derived from mechanical changes in the muscles, though a large component of the muscle stiffness was diminished with anesthetic thus was driven neurally (Synowiec et al., 2019).
During development, both feedback and feed-forward signaling can regulate growth and maturation, processes that may be disrupted in $\mathrm{CP}$ in both $\mathrm{MNs}$ and muscle fibers. It is likely the loss of spinal interneurons, MNs and muscle fibers reduce coordination and strength in those with CP. Altered size and excitability of MNs is also a feature of other motor disorders including amyotrophic lateral sclerosis and spinal muscular atrophy (Quinlan et al., 2011, 2019; Gogliotti et al., 2012; Shoenfeld et al., 2014; Dukkipati et al., 2018). Since our data were collected from multiple MN pools throughout the spinal cord, from control and HI injured rabbit kits, relatively large variability in parameters was expected (Kanning et al., 2010), however consistent differences in electrical properties emerged in this data set. This suggests consistent changes are present across motor pools after injury and support further exploration of interventions for $\mathrm{CP}$ and other motor disorders that target 

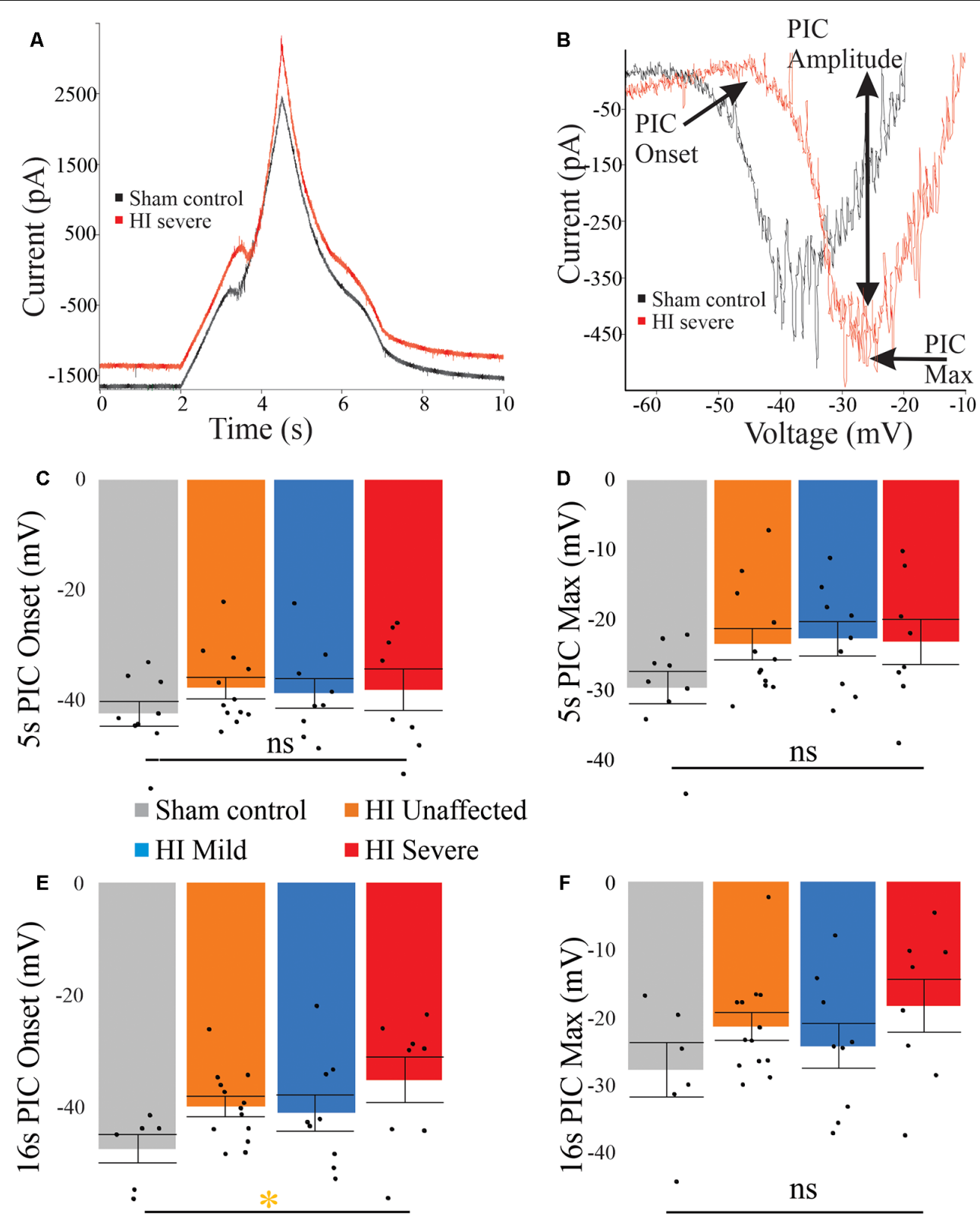

FIGURE 4 | PICs are altered in HI injured MNs. (A) The typical current response to a 5-s voltage ramp in a sham (black trace) and HI severe (red) MN. (B) Leak-subtracted PICs from panel (A) are similar in amplitude. There is a trend for depolarized PIC onset (C) in short ramps after HI injury, which reaches significance in long ramps (E). PIC Max did not reach significance (D) and (F). Error bars = SEM.

spinal MNs. These treatments could include neuromodulators and therapies aimed at restoring balance between excitation and inhibition within spinal circuits for alleviation of spasticity.

\section{Neuromodulation}

The exact causes of the changes in MN physiology observed here are unclear, but they could result from the increase in spinal monoamines that occurs after developmental HI injury in both rodents and rabbits (Bellot et al., 2014; Drobyshevsky et al., 2015). Serotonin is generally thought of as a neurotransmitter and neuromodulator, but developmental disruption in $5 \mathrm{HT}$ is associated with neurological disorders including autism, Rett syndrome, Down's syndrome and, more recently, CP (BarPeled et al., 1991; Whittle et al., 2007; Bellot et al., 2014; Yang et al., 2014; De Filippis et al., 2015; Drobyshevsky et al., 2015; Muller et al., 2016; Wirth et al., 2017). Serotonin increases MN excitability in neonatal and juvenile mice, rats and guinea pigs (Wang and Dun, 1990; Ziskind-Conhaim et al., 1993; Hsiao et al., 1997, 1998), and likely has the same effect on rabbit MNs. Depolarization of the resting membrane potential, increased action potential firing through hyperpolarization of the voltage threshold and enhanced PIC, increased action potential 

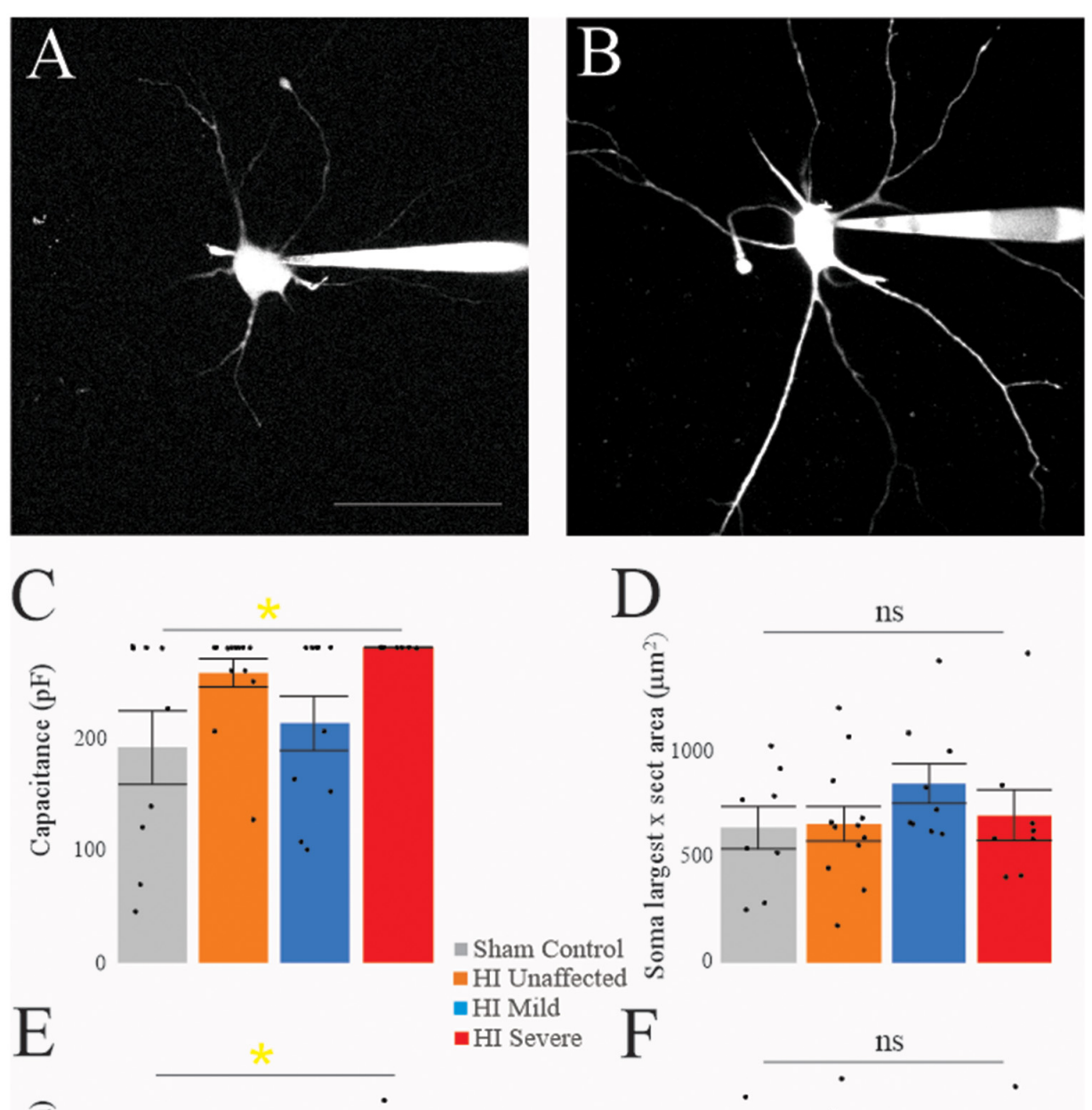

- HI Mild

- HI Severe

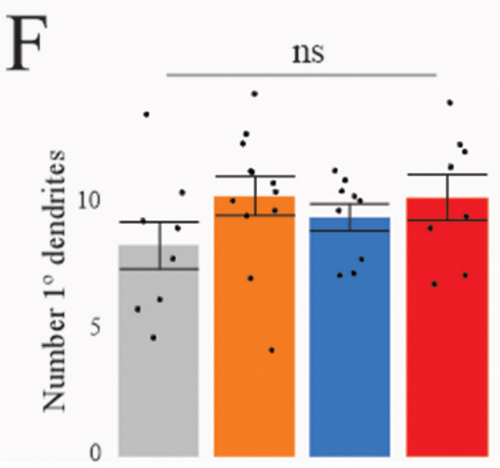

FIGURE 5 | Morphology is affected by HI. Typical sham control (A) and HI severe (B) MNs filled with dye during patch-clamp (electrodes visible on right). Average values of whole-cell capacitance (C), soma largest cross-sectional area (D), total dendrite length (E), and number of stem dendrites (F) are included for all neurons. Scale bar in $\mathbf{( A )}=100 \mu \mathrm{m}$ applies to $\mathbf{( A , B )}$. Error bars = SEM.

height and reduction of high-voltage activated $\mathrm{Ca}^{2+}$ entry are all associated with 5HT receptor activation in neonatal and adult MNs (Elliot and Wallis, 1992; Larkman and Kelly, 1992; Lindsay and Feldman, 1993; Bayliss et al., 1995; Hsiao et al., 1997, 1998; Inoue et al., 1999; Gilmore and Fedirchuk, 2004; Li et al., 2006). Therefore increased 5HT could have a direct impact on excitability, though in HI rabbits the increase in $5 \mathrm{HT}$ was accompanied by decreased mRNA for $5 \mathrm{HT}_{2}$ receptors and increased mRNA for the SERT serotonin transporter (Drobyshevsky et al., 2015). In light of that finding, it is not clear that neurons remain responsive to 5HT. In the experiments here, all MNs were recorded in spinal cord slices incubated and perfused in standard oxygenated aCSF without any serotonergic drugs present. Therefore, HI MNs in vivo could show different levels of excitability since they would be in the presence of elevated 5HT, while our MNs were all recorded in the same standard physiological solution. Thus, the contribution of 5HT to the altered excitability observed here is restricted to its chronic effects on neuron development, namely morphological changes. Serotonin $5 \mathrm{HT}_{1 \mathrm{~A}}$ and $5 \mathrm{HT}_{2 \mathrm{~A}}$ receptor activation increases neurite outgrowth, dendritic branching, and spine formation (Bou-Flores et al., 2000; Fricker et al., 2005; Mogha et al., 2012), 
findings that align well with the present finding of increased dendritic length in the HI MNs. Future experiments will be needed to address the role of 5HT in enhancing MN excitability and its effects on synaptically-evoked action potentials. Synaptic events in dendrites would more strongly evoke PICs, though both altered dendritic morphology and elevated 5HT could dampen them.

\section{Possible Mechanism of Altered MN Output}

The mechanism for increased $\mathrm{MN}$ activity and thus muscle stiffness may be due to delayed $\mathrm{Na}^{+}$channel inactivation. In neonatal $\mathrm{MNs}, \mathrm{Na}^{+}$channels generate the majority of the PIC and account for action potential initiation/repetitive firing. Specifically, Nav 1.1, 1.2 and 1.6 type $\mathrm{Na}^{+}$channels (Boiko et al., 2001, 2003; Rush et al., 2005) inactivate faster than $\mathrm{Ca}^{2+}$ channels that contribute to PICs (Perrier and Hounsgaard, 2003; Li et al., 2006). Short voltage ramps preferentially measure the $\mathrm{Na}^{+}$PIC for this reason: $\mathrm{Na}^{+}$channels inactivate quickly enough that even on the descending ramp of the short protocol, there is no longer a region of negative slope (see Figure 4). Changes in $\mathrm{Na}^{+}$channel inactivation in adult MNs along with postnatal development of the longer-lasting $\mathrm{Ca}^{2+}$ PIC makes typical adult MNs display more negative $\Delta \mathrm{I}$ values and longer-lasting PICs (Harvey et al., 2006; Li et al., 2006; Quinlan et al., 2011). In the neonatal rabbit MNs, sham controls showed positive $\Delta \mathrm{I}$ values that are quite typical for neonates, while $\mathrm{HI}$ MNs showed significantly more negative values. This could be due to slower $\mathrm{Na}^{+}$channel inactivation or increased contribution of $\mathrm{Ca}^{2+}$ channels to the PICs after injury. Interestingly the more depolarized resting potential found in HI severe MN would serve to increase $\mathrm{Na}^{+}$channel inactivation. To fully determine the altered mechanism of aberrant firing after HI injury future studies into the biophysical properties of $\mathrm{Na}^{+}$channels and maturation of $\mathrm{Ca}^{2+}$ channel expression must be pursued.

\section{Severity in Motor Deficits and Electrophysiology}

Generally, unaffected and mildly affected MNs showed parameters that were intermediate between control MNs and severe MNs. There was only one category in which mildly affected MNs become statistically significantly different from sham controls (instantaneous firing frequency). Thus, electrophysiological changes were overwhelmingly in line with phenotype, suggesting aberrant $\mathrm{MN}$ properties contribute to the severity of the phenotype. It cannot be ruled out, however, that HI "unaffected" MNs may have a subtle phenotype that is not readily evident based on testing we performed here. Or perhaps abnormalities in these rabbits would develop in later in life: in humans CP patients, diagnosis of CP is not made until 18-24 months of life and the peak of spasticity occurs around 4 years of age (Hägglund and Wagner, 2008; Hadders-Algra, 2014; Novak et al., 2017). In the rabbit model, deficits have not been characterized past P18, and a detailed analysis of the progression of motor deficits from $\mathrm{P} 0-18$ is lacking. Future work is needed to assess the maturation of the $\mathrm{MN}$ properties in different groups, the potential contribution of delayed $\mathrm{Na}^{+}$ channel inactivation in $\mathrm{CP}$, the progression of motor deficits with age, and the development of new therapeutic strategies that could target MNs.

\section{Postnatal Maturation and Injury}

The present study only extended from postnatal day $0-5$, but even within this narrow window, significant changes were apparent in $\mathrm{MN}$ electrical parameters. As MNs undergo postnatal maturation, they grow larger, with more complex dendritic arborizations, and gain the ability to fire action potentials at higher rates, as reviewed in Carrascal et al. (2005). We found that age had a significant effect on $5 \mathrm{~s}$ PIC amplitude (increasing with age), normalized PIC amplitude (both 5 and 16 s PIC/Cap increased with age), input resistance (decreasing with age), and action potential size, rate of rise and rate of fall (all increase with age). While neuron size increases during this period, the amplitude of the PIC typically increases more than proportionally (Quinlan et al., 2011). In other words, voltage-gated ion channels are being inserted into the membrane at a faster rate than the cell is increasing in size, resulting in an increased normalized PIC amplitude with age. We suspect this parallels the ability of MNs to fire action potentials at higher rates during postnatal development, and the acquisition of coordinated motor control and weight-bearing in developing animals.

\section{CONCLUSION}

Changes in MN physiology after developmental injury are consistent with motor deficits in rabbits. This suggests not only brain injuries but also changes in the spinal cord contribute to impaired function in CP. Exploring both altered maturation of spinal neurons and loss of descending connectivity should be pursued to improve outcomes for individuals with CP.

This manuscript has been released as a Pre-Print at BioRxiv (Steele et al., 2019).

\section{DATA AVAILABILITY STATEMENT}

All datasets generated for this study are included in the article/Supplementary Material.

\section{ETHICS STATEMENT}

The animal study was reviewed and approved by University of Rhode Island's, Northwestern University's and Northshore University Health System's Animal Care and Use Committees.

\section{AUTHOR CONTRIBUTIONS}

PS, CC, MG, and KQ wrote the manuscript. PS, CC, LD, MW, and $\mathrm{KQ}$ performed the experiments and analyzed the data. $\mathrm{AD}, \mathrm{MG}$, and KQ planned the experiments and interpreted the results. PS, CC, and NK performed statistical analysis. All authors approved the content and assisted in revision and review of manuscript. 


\section{FUNDING}

This project was supported by National Institutes of Health, NINDS R01NS091278 to AD and NINDS R01NS104436 to MG and KQ.

\section{REFERENCES}

Bar-Peled, O., Gross-Isseroff, R., Ben-Hur, H., Hoskins, I., Groner, Y., and Biegon, A. (1991). Fetal human brain exhibits a prenatal peak in the density of serotonin 5-HT1A receptors. Neurosci. Lett. 127, 173-176. doi: 10.1016/03043940(91)90787-t

Bayliss, D. A., Umemiya, M., and Berger, A. J. (1995). Inhibition of N- and P-type calcium currents and the after-hyperpolarization in rat motoneurones by serotonin. J. Physiol. 485, 635-647. doi: 10.1113/jphysiol.1995. sp020758

Bellot, B., Peyronnet-Roux, J., Gire, C., Simeoni, U., Vinay, L., and Viemari, J. C. (2014). Deficits of brainstem and spinal cord functions after neonatal hypoxiaischemia in mice. Pediatr. Res. 75, 723-730. doi: 10.1038/pr.2014.42

Boiko, T., Rasband, M. N., Rock, S., Caldwell, J. H., Mandel, G., Trimmer, J. S., et al. (2001). Compact myelin dictates the differential targeting of two sodium channel isoforms in the same axon. Neuron 30, 91-104. doi: 10.1016/s08966273(01)00265-3

Boiko, T., Van Wart, A., Caldwell, J. H., Levinson, S. R., Trimmer, J. S., and Matthews, G. (2003). Functional specialization of the axon initial segment by isoform-specific sodium channel targeting. J. Neurosci. 23, 2306-2313. doi: 10.1523/jneurosci.23-06-02306.2003

Bou-Flores, C., Lajard, A., Monteau, R., De Maeyer, E., Seif, I., Lanoir, J., et al. (2000). Abnormal phrenic motoneuron activity and morphology in neonatal monoamine oxidase a-deficient transgenic mice: possible role of a serotonin excess. J. Neurosci. 20, 4646-4656. doi: 10.1523/jneurosci.20-12-04646.2000

Brandenburg, J. E., Gransee, H. M., Fogarty, M. J., and Sieck, G. C. (2018). Differences in lumbar motor neuron pruning in an animal model of early onset spasticity. J. Neurophysiol. 120, 601-609. doi: 10.1152/jn.00186.2018

Buser, J. R., Segovia, K. N., Dean, J. M., Nelson, K., Beardsley, D., Gong, X., et al. (2010). Timing of appearance of late oligodendrocyte progenitors coincides with enhanced susceptibility of preterm rabbit cerebral white matter to hypoxia-ischemia. J. Cereb. Blood Flow Metab. 30, 1053-1065. doi: $10.1038 /$ jcbfm.2009.286

Carrascal, L., Nieto-gonzalez, L., Cameron, W. E., Torres, B., and Nunezabades, P. A. (2005). Changes during the postnatal development in physiological and anatomical characteristics of rat motoneurons studied in vitro. Brain Res. Rev. 49, 377-387. doi: 10.1016/j.brainresrev.2005.02.003

Cavarsan, C. F., Gorassini, M. A., and Quinlan, K. A. (2019). Animal models of developmental motor disorders: parallels to human motor dysfunction in cerebral palsy. J. Neurophysiol. 122, 1238-1253. doi: 10.1152/jn. 00233.2019

Clowry, G. J. (2007). The dependence of spinal cord development on corticospinal input and its significance in understanding and treating spastic cerebral palsy. Neurosci. Biobehav. Rev. 31, 1114-1124. doi: 10.1016/j.neubiorev.2007.04.007

Clowry, G. J., Basuodan, R., and Chan, F. (2014). What are the best animal models for testing early intervention in cerebral palsy? Front. Neurol. 5, 1-17. doi: 10.3389/fneur.2014.00258

Clowry, G. J., Davies, B. M., Upile, N. S., Gibson, C. L., and Bradley, P. M. (2004). Spinal cord plasticity in response to unilateral inhibition of the rat motor cortex during development: changes to gene expression, muscle afferents and the ipsilateral corticospinal projection. Eur. J. Neurosci. 20, 2555-2566. doi: 10.1111/j.1460-9568.2004.03713.x

De Filippis, B., Chiodi, V., Adriani, W., Lacivita, E., Mallozzi, C., Leopoldo, M., et al. (2015). Long-lasting beneficial effects of central serotonin receptor 7 stimulation in female mice modeling rett syndrome. Front. Behav. Neurosci. 9, 1-11. doi: 10.3389/fnbeh.2015.00086

Derrick, M., Luo, N. L., Bregman, J. C., Jilling, T., Ji, X., Fisher, K., et al. (2004). Preterm fetal hypoxia-ischemia causes hypertonia and motor deficits in the neonatal rabbit: a model for human cerebral palsy? J. Neurosci. 24, 24-34. doi: 10.1523/jneurosci.2816-03.2004

\section{SUPPLEMENTARY MATERIAL}

The Supplementary Material for this article can be found online at: https://www.frontiersin.org/articles/10.3389/fncel. 2020.00069/full\#supplementary-material.

Drobyshevsky, A., and Quinlan, K. A. (2017). Spinal cord injury in hypertonic newborns after antenatal hypoxia-ischemia in a rabbit model of cerebral palsy. Exp. Neurol. 293, 13-26. doi: 10.1016/j.expneurol.2017.03.017

Drobyshevsky, A., Takada, S. H., Luo, K., Derrick, M., Yu, L., Quinlan, K. A., et al. (2015). Elevated spinal monoamine neurotransmitters after antenatal hypoxia-ischemia in rabbit cerebral palsy model. J. Neurochem. 132, 394-402. doi: 10.1111/jnc.12997

Dukkipati, S. S., Garrett, T. L., and Elbasiouny, S. M. (2018). The vulnerability of spinal motoneurons and soma size plasticity in a mouse model of amyotrophic lateral sclerosis. J. Physiol. 596, 1723-1745. doi: 10.1113/ jp275498

Elliot, P., and Wallis, D. I. (1992). Serotonin and 1-norepinephrine as mediators of altered excitability in neonatal rat motoneurons studied in vitro. Neuroscience 47, 533-544. doi: 10.1016/0306-4522(92)90163-v

Fricker, A. D., Rios, C., Devi, L. A., and Gomes, I. (2005). Serotonin receptor activation leads to neurite outgrowth and neuronal survival. Mol. Brain Res. 138, 228-235. doi: 10.1016/j.molbrainres.2005.04.016

Friel, K., Chakrabarty, S., Kuo, H. C., and Martin, J. (2012). Using motor behavior during an early critical period to restore skilled limb movement after damage to the corticospinal system during development. J. Neurosci. 32, 9265-9276. doi: 10.1523/jneurosci.1198-12.2012

Friel, K. M., and Martin, J. H. (2005). Role of sensory-motor cortex activity in postnatal development of corticospinal axon terminals in the cat. J. Comp. Neurol. 485, 43-56. doi: 10.1002/cne.20483

Friel, K. M., and Martin, J. H. (2007). Bilateral activity-dependent interactions in the developing corticospinal system. J. Neurosci. 27, 11083-11090. doi: 10.1523/jneurosci.2814-07.2007

Gilmore, J., and Fedirchuk, B. (2004). The excitability of lumbar motoneurones in the neonatal rat is increased by a hyperpolarization of their voltage threshold for activation by descending serotonergic fibres. J. Physiol. Lond. 558, 213-224. doi: 10.1113/jphysiol.2004.064717

Gogliotti, R. G., Quinlan, K. A., Barlow, C. B., Heier, C. R., Heckman, C. J., and DiDonato, C. J. (2012). Motor neuron rescue in spinal muscular atrophy mice demonstrates that sensory-motor defects are a consequence, not a cause, of motor neuron dysfunction. J. Neurosci. 32, 3818-3829. doi: 10.1523/jneurosci. 5775-11.2012

Graham, H. K., Rosenbaum, P., Paneth, N., Dan, B., Lin, J.-P., and Damiano, D. L. (2016). Cerebral palsy. Nat. Rev. Dis. Prim. 2:15082. doi: 10.1038/nrdp. 2015.82

Hadders-Algra, M. (2014). Early diagnosis and early intervention in cerebral palsy. Front. Neurol. 5:185. doi: 10.3389/fneur.2014.00185

Hägglund, G., and Wagner, P. (2008). Development of spasticity with age in a total population of children with cerebral palsy. BMC Musculoskelet. Disord. 9:150. doi: 10.1186/1471-2474-9-150

Han, Q., Feng, J., Qu, Y., Ding, Y., Wang, M., So, K.-F., et al. (2013). Spinal cord maturation and locomotion in mice with an isolated cortex. Neuroscience 253 235-244. doi: 10.1016/j.neuroscience.2013.08.057

Harvey, P. J., Li, X., Li, Y., and Bennett, D. J. (2006). 5-HT 2 receptor activation facilitates a persistent sodium current and repetitive firing in spinal motoneurons of rats with and without chronic spinal cord injury. J. Neurophysiol. 96, 1158-1170. doi: 10.1152/jn.01088.2005

Hsiao, C. F., Del Negro, C. A., Trueblood, P. R., and Chandler, S. H. (1998). Ionic basis for serotonin-induced bistable membrane properties in guinea pig trigeminal motoneurons. J. Neurophysiol. 79, 2847-2855. doi: 10.1152/jn.1998. 79.6.2847

Hsiao, C. F., Trueblood, P. R., Levine, M. S., and Chandler, S. H. (1997). Multiple effects of serotonin on membrane properties of trigeminal motoneurons in vitro. J. Neurophysiol. 77, 2910-2924. doi: 10.1152/jn.1997.77.6.2910

Inoue, T., Itoh, S., Kobayashi, M., Kang, Y., Matsuo, R., Wakisaka, S., et al. (1999). Serotonergic modulation of the hyperpolarizing spike afterpotential in 
rat jaw-closing motoneurons by PKA and PKC. J. Neurophysiol. 82, 626-637. doi: 10.1152/jn.1999.82.2.626

Jiang, Y.-Q., Armada, K., and Martin, J. H. (2019). Neuronal activity and microglial activation support corticospinal tract and proprioceptive afferent sprouting in spinal circuits after a corticospinal system lesion. Exp. Neurol. 321:113015. doi: 10.1016/j.expneurol.2019.113015

Jiang, Y. Q., Sarkar, A., Amer, A., and Martin, J. H. (2018). Transneuronal downregulation of the premotor cholinergic system after corticospinal tract loss. J. Neurosci. 38, 8329-8344. doi: 10.1523/jneurosci.3410-17.2018

Jiang, Y.-Q., Zaaimi, B., and Martin, J. H. (2016). Competition with primary sensory afferents drives remodeling of corticospinal axons in mature spinal motor circuits. J. Neurosci. 36, 193-203. doi: 10.1523/jneurosci.3441-15.2016

Kanning, K. C., Kaplan, A., and Henderson, C. E. (2010). Motor neuron diversity in development and disease. Annu. Rev. Neurosci. 33, 409-440. doi: 10.1146/annurev.neuro.051508.135722

Larkman, P. M., and Kelly, J. S. (1992). Ionic mechanisms mediating 5-hydroxytryptamine- and noradrenaline-evoked depolarization of adult rat facial motoneurones. J. Physiol. 456, 473-490. doi: 10.1113/jphysiol.1992. sp019347

Li, Q., and Martin, J. H. (2000). Postnatal development of differential projections from the caudal and rostral motor cortex subregions. Exp. Brain Res. 134, 187-198. doi: 10.1007/s002210000454

Li, X., Murray, K., Harvey, P. J., Ballou, E. W., and Bennett, D. J. (2006). Serotonin facilitates a persistent calcium current in motoneurons of rats with and without chronic spinal cord injury. J. Neurophysiol. 97, 1236-1246. doi: 10.1152/jn. 00995.2006

Lindsay, A. D., and Feldman, J. L. (1993). Modulation of respiratory activity of neonatal rat phrenic motoneurones by serotonin. J. Physiol. Lond. 461, 213-233. doi: 10.1113/jphysiol.1993.sp019510

MacLennan, A., and International Cerebral Palsy Task Force (1999). A template for defining a causal relation between acute intrapartum events and cerebral palsy: international consensus statement. BMJ 319, 1054-1059. doi: 10.1136/bmj.319.7216.1054

Magee, L., Sawchuck, D., Synnes, A., van Dadelszen, P., Magnesium Sulphate For Fetal Neuroprotection Consensus Committee, and Maternal Fetal Medicine Committee (2011). SOGC clinical practice guideline. Magnesium sulphate for fetal neuroprotection. J. Obstet. Gynaecol. Canada 33, 516-529. doi: 10.1016/S1701-2163(16)34886-1

Marciniak, C., Li, X., and Zhou, P. (2015). An examination of motor unit number index in adults with cerebral palsy. J. Electromyogr. Kinesiol. 25, 444-450. doi: 10.1016/j.jelekin.2015.02.007

Martin, J. H., Kably, B., and Hacking, A. (1999). Activity-dependent development of cortical axon terminations in the spinal cord and brain stem. Exp. Brain Res. 125, 184-199. doi: 10.1007/s002210050673

Mogha, A., Guariglia, S. R., Debata, P. R., Wen, G. Y., and Banerjee, P. (2012). Serotonin $1 \mathrm{~A}$ receptor-mediated signaling through ERK and PKC $\alpha$ a is essential for normal synaptogenesis in neonatal mouse hippocampus. Transl. Psychiatry 2:e66. doi: 10.1038/tp.2011.58

Muller, C. L., Anacker, A. M. S. J., and Veenstra-VanderWeele, J. (2016). The serotonin system in autism spectrum disorder: from biomarker to animal models. Neuroscience 321, 24-41. doi: 10.1016/j.neuroscience.2015. 11.010

Novak, I., Mcintyre, S., Morgan, C., Campbell, L., Dark, L., Morton, N., et al. (2013). A systematic review of interventions for children with cerebral palsy: state of the evidence. Dev. Med. Child Neurol. 55, 885-910. doi: 10.1111/dmcn. 12246

Novak, I., Morgan, C., Adde, L., Blackman, J., Boyd, R. N., BrunstromHernandez, J., et al. (2017). Early, accurate diagnosis and early intervention in cerebral palsy: advances in diagnosis and treatment. JAMA Pediatr. 171, 897-907. doi: 10.1001/jamapediatrics.2017.1689

Perrier, J. F., and Hounsgaard, J. (2003). 5-HT2 receptors promote plateau potentials in turtle spinal motoneurons by facilitating an L-type calcium current. J. Neurophysiol. 89, 954-959. doi: 10.1152/jn.00753.2002
Quinlan, K. A., Reedich, E., Arnold, W. D., Puritz, A., Cavarsan, C. F., Heckman, C., et al. (2019). Hyperexcitability precedes motoneuron loss in the Smn 2B/- mouse model of spinal muscular atrophy. J. Neurophysiol. 122, 1297-1311. doi: 10.1152/jn.00652.2018

Quinlan, K. A., Schuster, J. E., Fu, R., Siddique, T., and Heckman, C. J. (2011). Altered postnatal maturation of electrical properties in spinal motoneurons in a mouse model of amyotrophic lateral sclerosis. J. Physiol. 589, 2245-2260. doi: 10.1113/jphysiol.2010.200659

Rouse, D. J., and Gibbins, K. J. (2013). Magnesium sulfate for cerebral palsy prevention. Semin. Perinatol. 37, 414-416. doi: 10.1053/j.semperi.2013.06.025

Rush, A. M., Dib-Hajj, S. D., and Waxman, S. G. (2005). Electrophysiological properties of two axonal sodium channels, Nav1.2 and Nav1.6, expressed in mouse spinal sensory neurones. J. Physiol. Lond. 564, 803-815. doi: 10.1113/jphysiol.2005.083089

Shoenfeld, L., Westenbroek, R. E., Fisher, E., Quinlan, K. A., Tysseling, V. M., Powers, R. K., et al. (2014). Soma size and Cavl.3 channel expression in vulnerable and resistant motoneuron populations of the SOD1G93A mouse model of ALS. Physiol. Rep. 2:e12113. doi: 10.14814/phy2. 12113

Steele, P. R., Cavarsan, C. F., Dowaliby, L., Westefeld, M., Drobyshevsky, A., Gorassini, M. A., et al. (2019). Altered motoneuron properties contribute to motor deficits in a rabbit hypoxia ischemia model of cerebral palsy. bioRxiv [Preprint]. doi: 10.1101/817957

Synowiec, S., Lu, J., Yu, L., Goussakov, I., Lieber, R., and Drobyshevsky, A. (2019). Spinal hyper-excitability and altered muscle structure contribute to muscle hypertonia in newborns after antenatal hypoxia-ischemia in a rabbit cerebral palsy model. Front. Neurol. 9, 1-18. doi: 10.3389/fneur.2018.01183

Thoresen, M., Bågenholm, R., Løberg, E. M., Apricena, F., and Kjellmer, I. (1996). Posthypoxic cooling of neonatal rats provides protection against brain injury. Arch. Dis. Child. 74, F3-F9. doi: 10.1136/fn.74.1.f3

Wang, M., and Dun, N. (1990). 5-Hyroxytryptamine responses in neonate rat motoneurones in vitro. J. Physiol. 430, 87-103. doi: 10.1113/jphysiol.1990. sp018283

Whittle, N., Sartori, S. B., Dierssen, M., Lubec, G., and Singewald, N. (2007). Fetal down syndrome brains exhibit aberrant levels of neurotransmitters critical for normal brain development. Pediatrics 120, e1465-e1471. doi: 10.1542/peds. 2006-3448

Wimalasundera, N., and Stevenson, V. L. (2016). Cerebral palsy. Pract. Neurol. 16, 184-194. doi: 10.1136/practneurol-2015-001184

Wirth, A., Holst, K., and Ponimaskin, E. (2017). How serotonin receptors regulate morphogenic signalling in neurons. Prog. Neurobiol. 151, 35-56. doi: 10.1016/j. pneurobio.2016.03.007

Yager, J., Towfighi, J., and Vannucci, R. C. (1993). Influence of mild hypothermia on hypoxic-ischemic brain damage in the immature rat. Pediatr. Res. 34 , 525-529. doi: 10.1203/00006450-199310000-00029

Yang, C. J., Tan, H. P., and Du, Y. J. (2014). The developmental disruptions of serotonin signaling may involved in autism during early brain development. Neuroscience 267, 1-10. doi: 10.1016/j.neuroscience.2014.02.021

Ziskind-Conhaim, L., Seebach, B. S., and Gao, B. X. (1993). Changes in serotonininduced potentials during spinal cord development. J. Neurophysiol. 69, 1338-1349. doi: 10.1152/jn.1993.69.4.1338

Conflict of Interest: The authors declare that the research was conducted in the absence of any commercial or financial relationships that could be construed as a potential conflict of interest.

Copyright (c) 2020 Steele, Cavarsan, Dowaliby, Westefeld, Katenka, Drobyshevsky, Gorassini and Quinlan. This is an open-access article distributed under the terms of the Creative Commons Attribution License (CC BY). The use, distribution or reproduction in other forums is permitted, provided the original author(s) and the copyright owner(s) are credited and that the original publication in this journal is cited, in accordance with accepted academic practice. No use, distribution or reproduction is permitted which does not comply with these terms. 